\title{
A influência da participação social para o desenvolvimento local. Estudo de caso em uma comunidade rural no nordeste do Brasil
}

\author{
Júlia Kátia Borgneth Petrus \\ Universidade Federal do Maranhão (UFMA) - São Luís / Maranhão /Brasil \\ E-mail: jpetrus@hotmail.com \\ Magno Vasconcelos Pereira Junior \\ Universidade de Barcelona, Barcelona, España. \\ E-mail: magnojr5@hotmail.com
}

\begin{abstract}
Resumo: Este artigo tem como objetivo analisar comportamentos comunitários rurais referentes à participação social. Eles integram um dos indicadores utilizados no estudo sobre capital social na Comunidade Cachoeira em Maranguape Ceará - Brasil. A participação social nos espaços rurais tem grande potencialidade de desenvolvimento, considerando a proximidade entre as pessoas e os laços que os unem, leva-os a relacionamentos interpessoais. No entanto, apesar de todas estas vantagens, nem sempre a participação social está presente nas comunidades rurais. No presente texto a participação é observada de forma limitada e limitante, onde cada um cuida de sua vida, apesar de haver certa preocupação com os mais próximos, porém, sem tomar decisões em nível coletivo. Com isso, o indicador de participação social no Distrito de Cachoeira, objeto de estudo deste trabalho, é classificado como baixo.
\end{abstract}

Palavras chaves: Distrito de Cachoeira, desenvolvimento, participação social, sujeito social.

\section{La influencia de la participación social para el desarrollo local. Estudio de caso en una comunidad rural en el nordeste de Brasil}

Resumen: Este artículo tiene como objetivo analizar comportamientos comunitarios rurales referentes a la participación social. Ellos integran uno de los indicadores utilizados en el estudio sobre capital social en la Comunidad Cachoeira en Maranguape Ceará - Brasil. La participación social en los espacios rurales tiene gran potencialidad de desarrollo considerando la proximidad entre las personas, y los lazos que los unen, que los lleva a relaciones interpersonales. Sin embargo, a pesar de todas estas ventajas, no siempre la participación social está presente en las comunidades rurales. En el presente texto la participación es observada de forma limitada y limitadora, donde cada uno cuida de su vida, a pesar de haber cierta preocupación con los más próximos, sin embargo sin tomar decisiones en nivel 
colectivo. Con eso, el indicador de participación social en el Distrito de Cachoeira, objeto de estudio de este trabajo, es clasificado como bajo. jeto social.

Palabras clave: Distrito de Cachoeira, desarrollo, participación social, su-

\title{
The influence of social participation for local development. Case study in a rural community in northeastern brazil
}

\begin{abstract}
This article has as aim to analyze rural community behaviors referring to social participation. They integrate one of indicators used in the study on social capital in the Community of Cachoeira in Maranguape Ceará - Brazil. The social participation in rural areas has great potential for development given the proximity between people, and the ties that unites them leads them to interpersonal relationships. However, although all these advantages, social participation is not always present in rural communities. In the present work participation is observed in a limited and restrictive manner, where each one takes care of his life, in spite having a certain concern with those close, yet without making decisions at a collective level. Thus, the indicator of social participation in Distrito of Chachoeira, object of this work's study, is classified as low.
\end{abstract}

Key words: Distrito de Cachoeira, development, social participation, social subject.

$* * *$

\section{Introdução}

No processo democrático está inserida a participação social, entretanto a oratória contradiz a realidade,mesmo com o pressuposto de que participação social é a distribuição de poder entre os membros de uma comunidade. Este fatojá originaum problema, dado que, segundo Pintaudi (2007):"sociedad y estado tienen objetivos contradictoriosenlo que respecta al poder. Y hay grados de subordinación al estado muy distintos entre miembros de una comunidad local”.O autordá ênfase a contradição da participação social efetiva e ao não interesse do Estado na participação dos sujeitos sociais, uma vez que tem objetivos diferentes: os dirigentes querem manter o status quo e a participação social pode ser uma ameaça aos interesses do "Estado".

No Brasil ainda há muitos governos locais centralizados, sobretudo no Nordeste, mesmo que atualmenteestejam se desenvolvendo políticas públicas que envolvem a participação do cidadão, onde os princípios de liberdade, igualdade e solidariedade estão inseridos.

Outro ponto a ser destacado é que a cultura brasileira está impregnada de medo, resignação e acomodação, fatores herdados da cultura autoritária vigente nos longos anos de ditadura militar. E, infelizmente, em muitas comunidades, esses sentimentos estão entranhadosnas mentes das pessoas. Participar deixa de ser uma premissa fundamental em comunidades, 
formandocidadãos fechados, submissos, suplicantes, dependentes, e até cínicos como bem menciona Putnam (1996: 191): "Já os cidadãos das regiões menos cívicas costumam assumir o papel de suplicantes cínicos e alienados”.

Quando se reportaà democracia participativa, subentende-se que o Estado reconhece os direitos dos cidadãos colocando a seu dispor mecanismos que os fortaleçam, formando cidadãos informados, atuantes, com poder de decisão, ou seja, revestidos deempowerment. Para isso, o poder público dever ser transparente, informando todas as suas ações, o que na prática não acontece. Então, a pergunta de Satori (2001):”de qué manera el pueblo está capacitado para ejercer el poder?’Para o autor, a educação e informação são fundamentais na tomada de decisão.Empoderar o povo, conforme Nascimento (2000), é um processo em que uma coletividade adquire poder a medida que fortalece laços de coesão, capacita-se e habilita-se para promover seu autodesenvolvimento.Nesse sentido, Romano(2002) explica que empoderar é uma abordagem que coloca aspessoas e o poder no centro dos processos de desenvolvimento;é um processo pelo qual aspessoas, as organizações, as comunidades tomam controle de seus próprios assuntos, de suaprópria vida e tomam consciência da sua habilidade e competência para produzir, criar e gerir. Como diz o dito popular: ser dono do seu próprio destino.

Sendo assim, pergunta-se: qual o interesse do Estado em educar, informar e empoderar seu povo?

Estamos diante de duas controvérsiasque impedema participação: uma de um povo culturalmente acomodado; à outra que, diante de todas as mazelas vividas pelos pobres com o aval do Estado, entende-se que este não tem interesse em instrumentalizar os cidadãos a seorganizarem. Porque,organizados, os cidadãosse empoderam, assim, a prática de participar se internalizaria no povo e o Estado, revestido de políticos manipuladores, teme, se apavora, com um povo que participa.

De todo modo, não se pode negar que há um esforço, desde a década de 80,em desenvolver novas formas de gestão pública por meio da participação. Um esforço de políticos inovadores, que visam o bem comum, e das próprias pessoas, principalmente daquelas que vivem em comunidade.

A Legislação Brasileira conta com inúmeros documentos que amparam e legalizam instrumentos de gestão pública através de debates, consultas e audiências públicas. Estes ganhos foram obtidos através da mobilização de movimentos sociais e de alguns políticos progressistas, que lutam pela participação social e vida digna para todos, diminuindo as desigualdades sociais.No entanto, para chegarà prática há ainda um longo caminho a se percorrer. Caminho que, em parte já se está percorrendo, pois já existem alguns ganhos reconhecidos, inclusive internacionalmente, como a luta dos Movimentos pela Anistia, as Diretas Já e o Impeachment do Presidente Fernando Collor de Melo. 
Uma das motivações deste trabalho é tentar compreender concepções, paradigmas que envolvem a participação social, suas percepções e práticas compartilhadas por uma comunidade no âmbito da ideia da organização social, que é uma vertente do capital social, este entendido como um conceito que caracteriza as várias maneiras de como os sujeitos atuam em sua comunidade.

Este é o grande desafio: definir e investigar participação social, na dimensão mais ampla da abordagem do capital social, buscando mostrar a importância deste para o desenvolvimento de qualquer país. O Brasil,país em questão neste texto,é marcado por características peculiares, pois, além da vastidão do seu território e sua enorme população, possui uma das sociedades mais desiguais do mundo. Silva Melo, no seu artigo "Desigualdade, Pobreza e Políticas de Transferência de Renda no Brasil" faz menção,

a persistência da desigualdade no Brasil está diretamente associada à naturalidade com que é encarada, como se não fosse a decorrência de um processo histórico específico, ou uma construção econômica, social e política deliberada (...). Desigualdade que resulta de um acordo social excludente, que não reconhece a cidadania para todos, onde a cidadania dos incluídos é distinta da dos excluídos e, em decorrência, também são distintos os direitos, as oportunidades e os horizontes (2013: 4).

Tratando-se de pessoas que vivem em comunidades rurais, a desigualdade social transformada em exclusão tem um lado ainda mais cruel, que é a internalização desta exclusão. Ela passa a ser vista como normal e é externalizada em expressões como:"faz parte da vida" ou "foi Deus quem quis assim”, a humilhação passa a fazer parte desse cotidiano de naturalidade.

Estas diferenças se agravam entre as regiões brasileiras, bastaobservar a região sul e compará-la com a região nordeste. Uma exprime os maiores índices de desenvolvimento e a outra os menores índices.

Dentre os estados brasileiros o Ceará situa-se entre os mais carentes, possuindo um percentual significativo de pobres. Segundo Machado et al (2009), logo de início, no resumo do seu artigo, são enfatizadas as mazelas cearenses.

O Ceará é um dos estados mais pobres do Brasil. Segundo dados da PNAD (2007) mais da metade (50,9\%) de sua população se encontra abaixo da linha de pobreza1, não tendo acesso aos meios necessários para uma sobrevivência humana digna. Além disso, apresenta o $7^{\circ}$ pior índice de desenvolvimento humano do país (Atlas do Desenvolvimento Humano do Brasil, PNUD, 2000). Não obstante, apresenta elevado nível de concentração de renda, refletido no coeficiente de Gini2 desse estado de 0,55 (IPEAData, 2007). Para o Banco Mundial (2003), o Ceará foi vítima de algumas deficiências 
estruturais inerentes ao Estado: “o desprezo pela formação profissional, saúde e condições de vida, especialmente dos mais pobres nas áreas rurais; a estrutura desigual da propriedade de bens e da distribuição de emprego; as instituições fracas e desiguais, em especial com histórico de concentração de poder, de cultura da desigualdade e, nos anos 1980, de gastos públicos, que deu origem a problemas fiscais; e a vulnerabilidade ao clima, às condições econômicas do restante do Brasil.” Essas deficiências contribuíram para o atual quadro de pobreza em que grande parte da população cearense está inserida.

Então, diante da investigação da realidade social, esta pesquisa agrega conhecimentos que afirmam que, dentre muitas opções de desenvolvimento, a participação social em comunidades rurais e periféricas deverá ser o início para um desenvolvimento justo e equitativo. Por meio de uma pesquisa científica pode-se contribuir para uma análise da influência da participação social em comunidades rurais.

Ancorado em textos e livros, este trabalho busca compreender e analisar, e ao mesmo tempo valorar e avaliar, a influência da participação social no desenvolvimento social,político e econômico, na comunidade do Distrito de Cachoeira, no Município de Maranguape - Ceará - Brasil.

\section{Marco conceitual}

A palavra participação vem do latim participare, e quer dizer fazer parte de algum grupo ou equipe, tomar parte numa determinada atividade ou negócio, inferir nas decisões, contribuir para construção de uma sociedade mais justa, mais igualitária.

Há autores que definem participação de um sujeito social como um mero participante, ele faz parte, mas não toma decisões e nem contribui para mudanças na comunidade em que vive.

Participação é uma necessidade do ser humano, não menor que a básica, o ser humano precisa interagir com o outro, fazer parte da sociedade, expressar-se, se sentir valorizado pelo outro.Portanto, a frustração de não participação se constitui uma violação do ser humano social, nesse contexto, homens e mulheresdesenvolverão seu pleno potencial em uma sociedade que os permitam e facilitem a participação social.

E nesse processo podem "cambiar las relaciones de poder del aparato produtivo y de lasociedad" (Itarraspe, 1986). O autor afirma que a participaçãoestá cada vez mais relevante nas comunidades, onde o fenômeno de participar faz com que seus membros fiquem mais desinibidos, sem medo de revelar sua opinião, e também lutem por seus ideais.

Para Itarraspe, a participaçãoestá intimamente ligada à 
descentralização, e somente dessa forma deixa de ser retórica para se tornar uma realidade.Quanto maior a participação, mais horizontais são as relações. Por outro lado, as relações verticais ocorrem em regiões sem hábito de participação, chegando a uma "suplicação vertical " ".

A participação social é uma forma de reivindicar do poder público, principalmente do executivo e legislativo, eleitos pelo sufrágio do povo, ações que beneficiem a comunidade como um todo. Pode-se dizer que aparticipação, quando bem comungada, traz o crescimento econômico, social e políticodo local.

O maior argumento para participar é o aumento das ações eficazes de políticas públicas que beneficiam o coletivo. Já a falta da participação é apontada como a principal causa de fracasso de programas e projetos. Logo, práticas participativas promovem o desenvolvimento que, segundo o Banco Mundial, "obriga" que haja um conjunto de normas transparentes e previsíveis que regulem as ações públicas e privadas.

O Relatório do Banco Mundial (2000-2001) “Luta contra a pobreza”, se refere à participação como condição essencial para a melhoria de vida no âmbito coletivo, afirmando que o

"fortalecimento das organizações de pobres pode ajudar a assegurar a prestação de serviços e adoção de políticas sensíveis às necessidades dos pobres e pode reduzir a corrupção e arbitrariedade das ações do Estado. Se os pobres puderem controlar a prestação de serviços sociais, é mais provável que o gasto público os ajude durante as crises. Finalmente, se os pobres receberem ajuda para enfrentar os choques e controlar os riscos, eles estarão numa posição melhor para aproveitar as novas oportunidades do mercado. Por isso, este relatório defende uma estratégia integral de luta contra a pobreza como condição fundamental para o processo de crescimento em geral.”

Quando o relatório se refere a fortalecer as organizações de pobres, entende-se o citado "fortalecimento" a partir da participação, que, no entender de muitos autores, é o único caminho para empoderar o pobre, onde este pode autogerir suas escolhas. Com muitas vozes erguidas pelos mesmos problemas (coletivos), incomodam, preocupam, aflijam de tal forma que podem impelir os governantes a ouvirem as vozes dos empoderados pobres, obrigando-os a agir a favor daquele coletivo de pouco, ou nada, favorecido.

Um artigo escrito por Gilson Schwartz, nos anos 2000 na Folha de São Paulo, intitulado "Controle social entra na pauta do Banco Mundial”, coloca em dúvida o empowermentdos pobres quando estes ainda não encontram um norte para a saída da exclusão econômica e consequentemente social. Sendo assim, este periodista desabafa: 
Ao fazer o deslocamento da questão social do campo da política econômica para o da participação política na distribuição de verbas sociais, a exclusão surge como uma falta de organização e consciência dos pobres.

Em tese, parece que se apresenta a oportunidade para a construção de uma nova utopia: os pobres, organizados, com voz e poder, seriam capazes de aumentar a transparência e a eficácia dos programas sociais.

Na prática, o que se observa é um círculo vicioso: o pobre não supera a exclusão porque não tem poder, mas ele não tem poder porque a pobreza é também uma forma de exclusão dos circuitos de educação, saúde e participação política.

O segundo parágrafo supracitadoé a negação da teoria relatada pelo Banco Mundial que afirma que "os pobres, organizados, com voz e poder, seriam capazes de aumentar a transparência e a eficácia dos programas sociais”. Como podem os pobres participarem,se são excluídos da educação, do pensar crítico, ou atémesmo impedidos de sonhar? Logo, a ordem seria educar para participar, contudo, agentes externos conscientes podem e devem ajudar comunidades a participar para que os outros fatores sejam agregados, tais como, educação, saúde, infraestrutura, etc.

Como já dizia Marx (1985), a emancipação humana só se completa quando o indivíduo tiver reconhecidos e organizados seus poderes sociais, de tal modo que não mais separe dele próprio esse poder social como poder político.A participação social diminui o sentimento de impotência dos indivíduos perante problemas que requerem soluções de cooperação mútua.Participar inibe oportunismo individual, pois as pessoas se envergonham de se aproveitar de vantagens em benefício próprio.

E para além de todas as vantagens em participar, o Estado tem ganhos imensuráveis. Para D’Araújo (2003: 30), a sociedade, para estar fortalecida e saudável, deve corrigir distorções para que não precise tanto do Estado, "seria assim, uma forma necessária, mas escapista, de transferir para a sociedade responsabilidades que o Estado estaria impossibilitado de assumir".

Portanto, a parceria entre sociedade e governo é reflexo da cooperação estreita entre estas, o que leva a pensar que, a participação social está intrinsecamente ligadaà uma sociedade forte e sadia o bastante para caminhar por si própria, e que consequentemente saiba se governar, ou escolher adequadamente seus governantes. Desse modo, pode-se pensar que o papel do Estado seria reduzido, mero engano, o Estado ficaria mais livre para cuidar de forma efetiva e eficaz de outras inúmeras necessidades coletivas, dando o que é de direito ao seu povo:o bem-estar.

Participação social é uma ferramenta endógena, evidentemente, se tratando de nível local, e no caso em questão, participação local rural. Robert Putmam, um grande estudioso do capital social, fez pesquisa na Itália, e 
afirma que o norte daquele país é mais desenvolvido economicamente do que o sul. O norte da Itália tem capital social, inclusive herdado dos antepassados, e sua cadeia de relações, confiança, cooperação, participação e de normas intrínsecas, como a reciprocidade, constitui os pilares de sua sustentação.

Putman (1996) credita o desenvolvimento do norte da Itália aos indicadores citados, incluindo a participação social e coletiva, daqueles que lutam pelo bem de todos da comunidade, portanto, pensa-se que os que participam, tem pelo menos o mínimo de cooperação, reciprocidade e confiança entre seus pares. Todavia, uma comunidade com pobreza multidimensional $^{2}$, tem mais dificuldade de internalizar a cultura da participação, por não entender sua força, a força da mudança. Ivo (2001: 44), acredita que deve ser construída uma nova hegemoniapautada na solidariedadealiadaà informação, como uma ferramenta de transformação.

É da perspectiva da construção de alternativas eformulação de nova hegemonia que se tem desenvolvido teses de desenvolvimento autossustentável, a qual supõe a construção de um poder local assentado numa nova cultura política, centrada na solidariedade como instrumento de libertação e articulação de energias sociais e politicas fragmentadas a partir do acesso à informação.

E aliado a tudo que já foi dito, uma pitada de revolta, não aceitando a condição de privação de suas escolhas ${ }^{3}$. E assim, mesmo com todas as adversidades, encontrar forças para participar, mudando a sua realidade e de sua comunidade, levando ao desenvolvimento social e local.

\section{Metodologia}

\section{Área de estudo}

A pesquisa foi realizada no distrito de Cachoeira, no município de Maranguape, localizado a $53 \mathrm{~km}$ ao sul de Fortaleza, capital do estado do Ceará, e a $28 \mathrm{~km}$ da sede do município. O distrito está situado à margem esquerda da rodovia CE 065, tendo como limites geográficos os municípios de Palmácia e Guaiuba. O objeto de estudo foi escolhido pela existência de um Comitê Agrícola neste local, o qual se destacava por seus membros produzirem e venderem coletivamente, por isso, entendeu-se que havia um mínimo de participação. Essas características despertaramo interesse da pesquisa in loco visando à constatação científica, ou não, da existência de participação social e sua contribuição para o desenvolvimento.

\section{População e amostra}

No Distrito de Cachoeira existem 184 famílias, totalizando aproximadamente 800 habitantes. O tamanho da amostra foi calculado utilizando uma amostragem aleatória simples, que cujo tamanho é baseado na fórmula de 
Fonseca e Martins (1996), cálculo conforme descrito abaixo.

$$
\begin{aligned}
& \mathrm{Z}^{2} \cdot \mathrm{p} \cdot \mathrm{q} \cdot \mathrm{N} \\
& \mathrm{N}= \\
& \mathrm{d}^{2}(\mathrm{~N}-1)+\mathrm{Z}^{2} \cdot \mathrm{p} \cdot \mathrm{q}
\end{aligned}
$$

Onde:

$\mathrm{N}=$ tamanho da amostra;

$\mathrm{Z}$ = abcissa da normal padrão;

$\mathrm{p}$ = estimativa da proporção da característica pesquisada no universo;

$\mathrm{q}=1-\mathrm{p}$

$\mathrm{N}$ = tamanho da população;

$\mathrm{d}=$ erro amostral.

Desse modo, de acordo com o cálculo da amostra em função do tamanho da população pesquisada, foram entrevistadas 63 famílias, residentes no Distrito de Cachoeira, tomadas aleatoriamente.

\section{Método de análise}

A investigação foi socialmente construída mediante interações constantes entre pesquisadores, pesquisados e a comunidade. Para a operacionalização do objeto de estudo, foi construído o Índice de participação social.

A seguir apresenta-se um conjunto de variáveis utilizadas no modelo, com seus respectivos escores, para aferira Participação Social no distrito de Cachoeira.

Participação social - Foi mensurada considerando o grau de participação do entrevistado e dos membros de sua família em atividades comunitárias, como escrito a seguir:

- Você faz parte de algum grupo?

- Você participa das reuniões do seu grupo?

- Algum membro da sua família faz parte de algum grupo?

- Você ou algum morador da sua casa tem algum relacionamento com grupos de fora da comunidade

- Participa de algum tipo de ação voluntária?

- Quantos amigos próximos você diria que tem hoje? Essas pessoas com quem se sente a vontade para conversar a respeito de assuntos particulares, ou chamar quando precisa de ajuda?

- Você acredita que tem amigos verdadeiros?

Com esse conjunto de variáveis pode-se construir o índice de participação social da comunidade de Cachoeira. 
Polis, Revista Latinoamericana, Volumen 15, No 44, 2016

\section{Resultado e discussão}

A comunidade de Cachoeira apresenta um nível de escolaridade pouco satisfatório. Os resultados apresentados na tabela 1 demonstram que 25,4\% dos entrevistados não são alfabetizados, ou seja, se muito, assinam apenas o seu nome. Dentre as 16 pessoas neste estado, 6 se encontram na faixa etária de 46 a 60 anos (37,5\%), 5 pessoas são maiores de 60 anos, o que equivale 31,2\%, 2 pessoas estão em idades de 31 a 45 anos (12,5\%) e 3 $(18,8 \%)$ estão na faixa de 16 a 30 anos.

\section{Tabela 1 - Frequência absoluta e relativa dos chefes de família segundo o grau de instrução}

\begin{tabular}{|c|c|c|}
\hline Grau de Instrução dos Entrevistados & Frequência Absoluta & Frequência Relativa (\%) \\
\hline Analfabetos/analfabetos funcionais & 16 & 25,4 \\
\hline Ensino Fundamental incompleto & 23 & 36,5 \\
\hline Ensino Fundamental completo & 05 & 8,0 \\
\hline Ensino Médio incompleto & 06 & 9,5 \\
\hline Ensino Médio completo & 12 & 19,0 \\
\hline Ensino Superior completo/incompleto & 01 & 1,6 \\
\hline TOTAL & 63 & 100,0 \\
\hline
\end{tabular}

FONTE: Dados da pesquisa

Elaboração dos autores

Quanto à renda per capta do Distrito de Cachoeira verifica-se na tabela 2 que $66,7 \%$ das famílias pesquisadas vivem com até $\mathrm{R} \$ 100,00^{4}$, ou seja, estas pessoas estão abaixo da linha da pobreza ${ }^{5}$.

\section{Tabela 2: Frequência absoluta e relativa das famílias segundo a renda per capita}

\begin{tabular}{|c|c|c|}
\hline Renda & Frequência absoluta & Frequência relativa (\%) \\
\hline Até $R \$ 100,00$ & 42 & 66,7 \\
\hline Entre R\$ 101,00 e R $\$ 200,00$ & 16 & 25,4 \\
\hline Entre R\$ 201,00 e R $\$ 300,00$ & 03 & 4,7 \\
\hline Entre R\$ 301,00 e R\$ 400,00 & 01 & 1,6 \\
\hline Entre R $\$ 401,00$ e R\$ 500,00 & 01 & 1,6 \\
\hline Acima de R\$ 500,00 & 00 & 0,0 \\
\hline TOTAL & 63 & 100,0 \\
\hline
\end{tabular}

Fonte: Dados da pesquisa

Elaboração dos autores 
De acordo com os dados do IPEA (2000), 58,0\% dos cearenses vivem abaixo da linha da pobreza. De 7,1 milhões de cearenses 4,1 milhões são pobres, e mais da metade foi classificada como indigente, ou seja, 2,2 milhões, no entanto a renda per capita saltou de $\mathrm{R} \$ 118,00$ para $\mathrm{R} \$ 161,00$, neste mesmo ano.

A renda per capita do Distrito de Cachoeira é de $\mathbf{R} \mathbf{9 3}$, 37, muito abaixo da renda dos cearenses, portanto, estão abaixo da linha da pobreza e se aproximando da linha de indigência. Comparando a renda per capita dos cearenses com a população estudada observa-se que estes recebem o equivalente a 58\% de R $\$ 161,00$.

O indicador participação do Distrito de Cachoeira, através da amostra da população da comunidade estudada, foi $\mathbf{0 , 4 3 6}$, portanto, está classificado como um indicador baixo. Foram utilizadas para medir o referido indicador sete variáveis.

Quando perguntados se alguém da família pesquisada faz parte de algum grupo27 (42,9\%) dos entrevistados responderam que não participam de nenhum grupo na comunidade, e 36 (57,1\%) declararam participar.

A tabela 3demonstra que dos 57,1\% das famílias que participam de alguma atividade comunitária, 64,0\% fazem parte da Associação Comunitária existente na comunidade e 39,0\% do Grupo Religioso, isto somando os percentuais dos que participam dos dois grupos. Já o percentual de pessoas que fazem parte do Comitê Agrícola é bem menor, 11,1\%, talvez em razão de problemas com a Presidência desta entidade, pois, segundo algumas informações, este Comitê Agrícola já foi bastante atuante. Apenas 5,6\% dos entrevistados pertencem ao Grupo da Melhor Idade.

\section{Tabela 3: Frequência absoluta e relativa das famílias que participam de atividade comunitária}

\begin{tabular}{|c|c|c|}
\hline Atividade Comunitária & Frequência Absoluta & Frequência Relativa (\%) \\
\hline Associação & 16 & 44,5 \\
\hline Grupo Religioso & 07 & 19,5 \\
\hline Comitê Agrícola & 04 & 11,1 \\
\hline Grupo da Melhor Idade & 02 & 5,6 \\
\hline Dois grupos $(*)$ & 07 & 19,5 \\
\hline TOTAL & 36 & 100,0 \\
\hline
\end{tabular}

(*) Os dois grupos do qual as pessoas participam são: Associação e Grupo Religioso.

FONTE: Dados da pesquisa

Elaboração dos autores 
Outra variável importante para mensurar o indicador de participação é a frequência às reuniões por aqueles que estão envolvidos em algum tipo de grupo na comunidade de Cachoeira. Dos 36 entrevistados que participam de reuniões, $50,0 \%$ as frequentam sempre, 38,9\% participam na maioria das vezes e, apenas, $11,1 \%$ só se fazem presentesquando o assunto é de seu interesse (Tabela 4).

\section{Tabela 4 - Frequência absoluta e relativa das famílias que participam das reuniões do grupo}

\begin{tabular}{|c|c|c|}
\hline Reunião de Grupo & Frequência Absoluta & Frequência relativa (\%) \\
\hline Sempre & 18 & 50,0 \\
\hline Na maioria das vezes & 14 & 38,9 \\
\hline Apenas quando $o$ assunto interessa & 04 & 11,1 \\
\hline TOTAL & 36 & 100,0 \\
\hline
\end{tabular}

FONTE: Dados da pesquisa

Elaboração dos autores

Apenas 13 pessoas das famílias entrevistadas têm atitudes voluntárias. Voluntário, segundo o Dicionário Aurélio, é aquele que age espontaneamente, por vontade própria, sem coação. Uma comunidade deve ter essa visão, mas sem se deixar explorar, pois ser voluntário também tem outro lado: fazer um trabalho que deveria ser pago e o Estado sabiamente reduz seus custos através do voluntariado.

A maioria dos moradores de Cachoeira não participa de qualquer grupo de fora da sua comunidade $(93,6 \%)$ apenas 4 pessoas disseram que sim, perfazendo um percentual de 6,4\%.

Quando foram questionados se têm amigos em quem podem confiar, somente 12,7\% disseram que não, 22,2\% têm muitos amigos e 65,1\% têm poucos ou mais ou menos amigos (Tabela 5). E apenas 14, num universo de 63 entrevistados, relataram que tinham muitos amigos, com os quais podem contar, em caso de alguma necessidade. 
Tabela 5 - Frequência absoluta e relativa dos entrevistados segundo o número de amigos

\begin{tabular}{|c|c|c|}
\hline Número de amigos & Frequência Absoluta & Frequência relativa (\%) \\
\hline Muitos & 14 & 22,2 \\
\hline Poucos & 20 & 31,8 \\
\hline Mais ou menos & 21 & 33,3 \\
\hline Nenhum & 08 & 12,7 \\
\hline TOTAL & 63 & 100,0 \\
\hline
\end{tabular}

FONTE: Dados da pesquisa

Elaboração dos autores

Quando perguntados se estes amigos são capazes de ajudar no que for preciso, inclusive emprestando dinheiro, 76,2\%, ou seja, 48 dos entrevistados, responderam que definitivamente os seus amigos os ajudariam, $11,1 \%$ não tem certeza de ter amigos e $12,7 \%$ creem que definitivamente não tem amigos (Tabela 6).

\section{Tabela 6 - Frequência absoluta e relativa dos entrevistados segundo o grau de amizade verdadeira}

\begin{tabular}{lc|c}
\hline \multicolumn{1}{c|}{ Grau de amizade } & Frequência Absoluta & Frequência relativa (\%) \\
\hline Definitivamente & 48 & 76,2 \\
Não tem certeza & 07 & 11,1 \\
Definitivamente não & 08 & 12,7 \\
\hline & 63 & 100,0 \\
\hline
\end{tabular}

FONTE: Dados da pesquisa

Elaboração dos autores

Portanto, por meio da análise ora demonstrada, compreende-se o porquê de o indicador de participação estar classificado como baixo, a comunidade tem ainda uma participação muito tímida, mesmo sendo uma comunidade prestativa, calorosa e acolhedora. Todavia, ainda precisa melhorar muito, precisa tomar mais consciência da importância da organização social para o seu progresso.

Alguns autores acreditam que a escolaridade é um fator que afeta o grau de participação, principalmente em atividades políticas e sociais; dizem ainda que, com o aumento do número de anos de estudo, cresce gradativa e regularmente a proporção de pessoas que participam de atividades que dizem respeito ao coletivo. 
A Associação e o Comitê Agrícola existentes na comunidade não têm estado na ativa. Mesmo quando há reuniõesdos pouco participantes, ainda não tomam decisões, deixando-as nas mãos do presidente. “A qualidade de decisões obtidas por meio da participação sempre dependerá do grau de capacitação da comunidade” (BANDEIRA, 1999: 31).

Convém evidenciar que o conceito de participação adotado pelo Banco Mundialé "um processo pelo meio do qual os indivíduos e as instituições afetadas por iniciativas de desenvolvimento podem influenciar a tomada de decisões dos recursos relacionados com essas iniciativas”.

Para que haja promoção do desenvolvimento é imprescindível que os sujeitos sociais se articulem, se unam, e isto não acontece sem participação. Bandeira (1999: 10) diz que uma das linhas de argumentação que vincula a participação à acumulação de capital social é a que afirma que:

o capital social [...] que é composto por um conjunto de fatores de natureza cultural que aumenta a propensão dos atores sociais para colaboração e para empreender ações coletivas - constitui-se em importante fator explicativo das diferenças regionais quanto ao nível de desenvolvimento.

Bandeira (1999) quer dizer que, se em uma comunidade existem sujeitos sociais empenhados no progresso local é porque eles participam e, inevitavelmente, promovem o desenvolvimento. Portanto, o desenvolvimento nacional, regional ou local está vinculado ao nível de participação das pessoas, pois, quanto menor este nível, menor o progresso, quanto maior, maior a possibilidade de desenvolvimento econômico, social e político.

A falta de participação em uma sociedade é apontada pela literatura de instituições, principalmente internacionais, como uma das maiores causas de fracasso de políticas públicas, projetos e programas, tornando-as incapazes de alcançar os objetivos propostos.

Os pesquisadores têm observado, em trabalhos comunitários no Maranhão, que muitos projetos do Estado, financiados pelo Banco Mundial a fundo perdido, como: casa de farinha, usina de arroz e outros, não são utilizados pela comunidade e estão se deteriorando. Há duas questões suscitadas pelas próprias comunidades: a primeira é a falta de consulta em relação aos projetosexecutados, ou seja, a definição do que a comunidade precisa não parte deles, mas resulta de decisões tomadas de cima para baixo, inviabilizando o projeto, e gerando perdas para a comunidade; a outra questão é a falta de união dos sujeitos sociais. A solução chama-se participação e quando esta existe, os projetos são demandados pelas pessoas que vivem aquela realidade. Portanto, a incompatibilidade de ações do poder público e comunidades que não têm o hábito de participação têm como consequência a falta de envolvimento, que impossibilita alcançar os objetivos propostos, au- 
mentando o risco destes projetos se tornarem efêmeros, envolvendo grande desperdício de recursos.

Bandeira (1999) alerta para a importânciada promoção de articulação entre os sujeitos sociais, fortalecendo a coesão da comunidade e melhorando a qualidade das decisões, assim tornando mais fácil o alcance de objetivos de interesse comum. As práticas participativas, no entanto, não podem ser encaradas como procedimentos infalíveis, capazes de sempre proporcionar soluções adequadas para os problemas comunitários, havendo outros fatores aliados à participação para que as relações sociais comunitárias possam ser eficientes e eficazes, tais como: confiança, valores e outros.

\section{Considerações finais}

A pesquisa relata que, do total dos entrevistados do distrito de Cachoeira, 25,4\% são pessoas não alfabetizadas e 31,2\% são idosos. Cruzando os dados, descobre-se que a maioria dos não alfabetizados são idosos. Todavia, o que mais chama atenção é a pobreza absoluta, aquela que leva em conta somente o econômico, ou seja, a renda per capita da comunidade, que é de R\$93,37. Contudo, segundo os dados do Ipea de 2009, “há 930 mil cearenses vivendo em condições de pobreza extrema, 130 mil a mais do que em 2008. O Ipea considera como extremamente pobre o indivíduo que tem renda per capita mensal inferior a $\mathrm{R} \$ 67,07$ ”. Mesmoque a comunidade em questão esteja acima do valor considerado pelo Ipea como de extrema pobreza, quase toda população do Distrito de Cachoeira, 96,8\%, ganham até um salário mínimo.

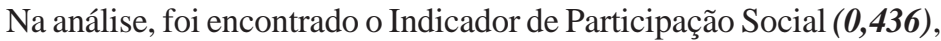
classificado como baixo, e juntamente com a percepção in loco, observouse que a participação socialestádespertando, contudo, precisa de interferência de agentes externos.

Segundo Abramovay, os agentes externos sãonecessários quando não há cultura de capital social em uma comunidade, pois, como já foi dito nesse trabalho, a participação é um dos pilares imprescindíveis na formação deste.

Também, para aumentar o capital social local, sugerimos que as lideranças comunitáriasinvistam na formação participativa dos jovens do Distrito de Cachoeira, bem como, instiguem as potencialidades das vocações individuais e coletivas.

Baseado nos resultados da pesquisa pode-se dizer que a referida comunidade, apesar de ter fortes laços de relacionamento coletivo, de ter preciosos valores e sentimento de pertencimento,precisa fortalecer o espírito coletivo e de justiça social, elevar sua estima e calcificar a ideia de organização social. Precisam entender que somente por meio desta, os pobres podem se valer de seus direitos. 
Hoje, todos os que partilham a cultura e a crença daparticipação levam, ao invés de certezas, interrogações, mas nãose submetem a capacho. Mas acredita-se que o ser humano vitorioso não é egoísta, mas homens e mulheres que sabem participar, partilhando os benefícios coletivamente.

Este resultado que é fruto de uma investigação em uma comunidade pequena, que tem todas as ferramentas para trabalhar unida em proldo coletivo deles, certamente abala as esperanças, mas

É desconfortável caminhar no escuro, acostumar-se à ausência de certezas. Mas podemos ver que as incertezas não paralisam a ação coletiva. Não destroem a teimosa construção de vínculos solidários de responsabilidade pelo destino comum dos seres humanos (Carvalho, 1989).

E uma das únicas formas de transformar uma situaçãonão confortável, em todos os âmbitos na situação desejada, ou seja, tornar realidade a situação confortável para o coletivo (como melhor educação, saúde, estradas, saneamento básico,etc.), é por meio da participação social. 


\section{Notas}

${ }^{1}$ Ideia usada por Putnam, para pessoas de região sem a cultura da reciprocidade, quando estas se acostumam às relações de cima para baixo, a relações de dependência do outro que tem uma posição "superior” na sociedade.

${ }^{2}$ Pobreza Multidimensional alude não somente a pobreza de privação das necessidades básicas, mas a privação dos seus direitos sociais no âmbito do território. Falamos em pobreza multidimensional quando a população carece de serviços básicos, de infraestrutura, de transporte público, educação, saúde, etc.

3 Para Amartya Sen a pobreza é definida como privação de capacidades básicas, ou seja, a perda da capacidade leva a perda de liberdade de escolhas. Sen enfatiza que essas perdas não se restringemsomente a renda baixa. A liberdade de escolhas se aplica a cada pessoa, a cada realidade, o que pode ser importante para uns, pode não ser para outros, leva em conta o respeito à cultura individual, de cada sociedade, contando que para erradicar a pobreza é preciso que o ser humano tenha o livre arbítrio para suas escolhas.

${ }^{4}$ Considerando que osalário mínimo do ano em que foi realizadaa pesquisa era de $\mathrm{R} \$$ 300,00 (2007).

${ }^{5}$ Segundo Relatório do Desenvolvimento Humano (1997), linha de pobreza indica insuficiência de recursos econômicos para satisfazer as necessidades básicas mínimas de alimentação. É utilizada pelo Banco Mundial para comparações internacionais, a linha de pobreza estabelecida em 1 dólar norte-americano por dia (renda per capita). Para a América Latina e Caribe é sugerida uma linha de pobreza de 2 dólares norte-americanos por dia. 
Polis, Revista Latinoamericana, Volumen 15, No 44, 2016

\section{Bibliografía}

Abramovay, Ricardo. (1998), A formação de capital social para o desenvolvimento local sustentável. São Luís, mimeo - Texto para discussão.

Ídem (1998), Capital social e desenvolvimento local: Alguns Apontamentos Teóricos. mimeo - Texto para discussão.

Ídem (2000), Capital social dos territórios: repensando o desenvolvimento rural, mimeo - Texto para discussão.

Banco Mundial (2002), Relatório sobre o Desenvolvimento Mundial: Luta contra a pobreza de 2000/2001- Panorama Geral. Oxford University Press, Banco Mundial, Estados Unidos.

Banco Mundial. Disponível em: http://www.obancomundial.org

Banco Nacional de Desenvolvimento Econômico e Social - BNDES. Disponível em: http://federativo.bndes.gov.br

Bandeira, P. (1999), Participação, articulação de atores sociais e desenvolvimento regional. IPEA, fev. Texto para discussão nº 630, Brasília.

Carvalho, Maria do Carmo (1998), Participação Social no Brasil hoje. Artigo, Instituto Polis.

Ferreira, Aurélio Buarque DE H. (1988), Dicionário Aurélio da língua portuguesa básica. Editora Nova Fronteira, Rio de janeiro.

Fonseca, J.S; Martins, G. A. (1996), Curso de estatística, Atlas, São Paulo.

Instituto de Pesquisa Econômica Aplicada - IPEA. Disponível em: http:// www.ipea.gov.br

Instituto de Pesquisa Econômica Aplicada/ CE - IPLANCE -CE. Disponível em:http://www.ipea.gov.br

Ivo, A. B. L. (2001), Metamorfoses da questão democrática:governabilidade e pobreza. Clacso, Buenos Aires.

Machado, Antonio Fabricio Santil; Silva, Maria Micheliana da Costa; Lemos, José de Jesus Sousa (2009), "Indicadores de Exclusão Social e Mitigação de Pobreza No Ceará”. In: Econtro de Economia do Ceará em Debate, 5, Anais Fortaleza: IPECE, Fortaleza.

Marx, Karl (1985), O Capital: crítica da economia política, $2^{\mathrm{a}}$ edição, Nova Cultural, São Paulo.

Nascimento, H. M. (2000), Capital Social e Desenvolvimento Sustentável 
no Sertão Baiano: A Experiência de Organização dos Pequenos Agricultores do Município de Valente. Dissertação de Mestrado apresentada ao Instituto de Economia da UNICAMP, Campinas.

Pintaudi, Silvana Maria. (2007), Presupuesto Participativo en Brasil: Consideraciones sobre la Participación Ciudadana. International Conference Direct Democracy en LatinAmerica. Buenos Aires, Argentina, Prefeitura Municipal de Maranguape. Disponível em: http:// www.maranguape.ce.gov.br

Programa das Nações Unidas para o Desenvolvimento - PNUD (2004), Relatório do desenvolvimento humano. Disponível em: http:// www.pnud.org.br/pobreza_desigualdade

Putnam, Robert (1996), Comunidade e Democracia: A experiência da Itália Moderna. Rio de Janeiro, FGV.

Satori, G. (2001), Homo Videns, televisão e pós-pensamento. Bauru, SP. EDUSC.

Silva Melo, Sonia Rebouças (2013), “Desigualdade, Pobreza e Políticas de Transferência de Renda no Brasil”. Revista Oidles - Vol 7, № 15.

Romano, Jorge O. (2002), Empoderamento: Enfrentaremos Primeiro a Questão do poder para Combater juntos a pobreza. International Workshop Empowerment and Rights Based Approach in Fighting Poverty Together, Rio de Janeiro, Brazil. 